\title{
Improvement of Resistance of MgO-Based Refractory to Slag Penetration by In Situ Spinel Formation
}

\begin{abstract}
HUIJUN WANG, BJÖRN GLASER, and DU SICHEN
MgO-in situ spinel substrate was prepared at $1773 \mathrm{~K}\left(1500^{\circ} \mathrm{C}\right)$ using colloidal alumina suspension and coarse $\mathrm{MgO}$ as raw materials. While the addition of 10 mass pct colloidal alumina had limited effect, addition of 20 mass pet colloidal alumina into the $\mathrm{MgO}$ matrix improved greatly the resistance of the substrate against the slag penetration at $1873 \mathrm{~K}\left(1600^{\circ} \mathrm{C}\right)$. The improvement was found to be mainly related to the formation of solid phases, $\mathrm{CaO} \cdot \mathrm{Al}_{2} \mathrm{O}_{3}$ and $\mathrm{CaO} \cdot \mathrm{MgO} \cdot \mathrm{Al}_{2} \mathrm{O}_{3}$ at the grain boundaries due to slag-spinel reaction. Putting the reacted substrate into contact again with new slag revealed no appreciable new slag penetration. The results showed a potential solution to improve the resistance of $\mathrm{MgO}$-based refractory to slag penetration and to improve steel cleanness.
\end{abstract}

DOI: $10.1007 / \mathrm{s} 11663-014-0277-7$

(C) The Minerals, Metals \& Materials Society and ASM International 2014

\section{INTRODUCTION}

THE role of ladle glaze as an important source of the formation of inclusions has evidently been reported. ${ }^{[1-8]}$ Ladle glaze is formed during the casting process. The top slag adheres to the ladle lining, while it goes down following the steel melt during the draining of the ladle. After the first heat, a decarburized layer is formed on the original $\mathrm{MgO}-\mathrm{C}$ refractory. The decarburized layer is usually porous. The adhered slag penetrates into the open pores of the refractory. After casting, two layers are found above the decarburized refractory in the wall of a $\mathrm{MgO}-\mathrm{C}$ lined ladle, viz. a slag-infiltrated layer and the outer slag layer. While the outer layer of the glaze would be removed during the filling of the ladle in the next heat, the slag-infiltrated layer would not be easily removed because of the $\mathrm{MgO}$ matrix. The movement of the liquid steel near the wall would flush off the tiny particles (droplets) from the slag-infiltrated layer resulting in calcium aluminate inclusions. The slag infiltration followed by flushing off of tiny particles (droplets) from the lining in the next heat is a self-acceleration process. The process would be enhanced when a ladle becomes older (more porous). In order to reduce the number of inclusions introduced by the refractory lining, blocking the pores of the $\mathrm{MgO}$ matrices and reducing the slag infiltration are essential.

In situ spinel (magnesia aluminate, $\mathrm{MgO} \cdot \mathrm{Al}_{2} \mathrm{O}_{3}$ )bonded magnesia ceramic has been recognized as one of effective refractories in all parts of ladle furnaces, since Eusner and Hubble ${ }^{[9]}$ first developed spinelbonded magnesia-based bricks. As a substitute of

HUIJUN WANG, Graduate Student, BJÖRN GLASER, Senior Researcher, and DU SICHEN, Professor, are with Department of Materials Science and Engineering, Royal Institute of Technology, 10044 Stockholm, Sweden. Contact e-mail: sichen@kth.se

Manuscript submitted October 10, 2014.

Article published online January 6, 2015. carbon-bonding, $\mathrm{MgO} \cdot \mathrm{Al}_{2} \mathrm{O}_{3}$ spinel offers a good improvement in both physical and chemical properties of $\mathrm{MgO}$-based refractories, such as densification, slag penetration resistance, and thermal shock resistance. ${ }^{[10]}$ A number of researchers have focused on the corrosion behavior between spinel- $\mathrm{MgO}$ and slag. Goto and coworkers ${ }^{[11]}$ have found that $\mathrm{CaO}-\mathrm{Al}_{2} \mathrm{O}_{3}-\mathrm{SiO}_{2}$ slag penetrated into $\mathrm{MgO}-\mathrm{MgO} \cdot \mathrm{Al}_{2} \mathrm{O}_{3}$ spinel bricks could lead to the formation of secondary spinel, $\mathrm{CaMgSiO}_{4}$, $\mathrm{Ca}_{3} \mathrm{MgSi}_{2} \mathrm{O}_{8}$, and $\mathrm{MgO}$ as microscopic corrosion products. Recently, aluminum oxide as an addition was added into MgO-C refractory by Ganesh et al. ${ }^{[12,13]}$ They found that refractories containing in situ spinel improved ceramic bonding and corrosion resistance. Some studies ${ }^{[14-16]}$ have also been conducted to investigate the corrosion mechanism in the $\mathrm{MgO}-\mathrm{Al}_{2} \mathrm{O}_{3}$ refractories. The factors including the pore size distribution, the change of liquid viscosity, and chemical reactions have been considered to evaluate the slagrefractory interaction. Besmann and $\mathrm{Luz}^{[17,18]}$ have described the chemical reaction mechanisms between slag and refractory, as well as the changes in liquid slag composition after corrosion by thermodynamic calculation. However, the detailed analysis of microstructure and phase evolution by slag penetration has not been addressed sufficiently so far.

Despite many advantages of in situ spinel bonding, expansion difference between spinel and $\mathrm{MgO}$ is considered as one of the most serious drawbacks, which hinders the potential applications of this material. To control the expansion, the incorporation of finer particles in MgO-based refractory is one of the effective approaches. More recently, Braulio studied the effect of alumina particle size on controlling the expansion of alumina-magnesia refractories. ${ }^{[19,20]}$ It was found that colloidal alumina suspension with nanoscale size presented the best performance.

In the present work, in situ spinel is formed by reaction between colloidal alumina and $\mathrm{MgO}$ matrix. The main purpose of the work is to investigate the 
penetration behavior of ladle slag on $\mathrm{MgO}$-in situ spinel substrates at $1873 \mathrm{~K}\left(1600{ }^{\circ} \mathrm{C}\right)$. The study focuses on the mechanism of the reaction between slag and refractory and the effect of the amount of alumina addition on slag penetration. The study is the first step to develop refractory for ladle line that can be used for the production of extra clean steel.

\section{EXPERIMENTAL PROCEDURE}

\section{A. Materials and Sample Preparation}

Coarse $\mathrm{MgO}$ powder (>98 pct purity) supplied by Sigma Aldrich was used as the matrix material. The particle size was 60 mesh $(<300 \mu \mathrm{m})$ with a BET specific surface area of $2.82 \mathrm{~m}^{2} / \mathrm{g}$. Colloidal alumina suspension (50 pct in $\mathrm{H}_{2} \mathrm{O}, 45 \mathrm{~nm}$ of average particle size) was used as addition to the $\mathrm{MgO}$ powder. The colloid was obtained from Alfa Aesar. To prepare the ceramic sample, $\mathrm{MgO}$ powder and colloidal alumina (the percentage corresponds to $\mathrm{Al}_{2} \mathrm{O}_{3}$ without $\mathrm{H}_{2} \mathrm{O}$ ) in desired proportions were mixed in a ceramic mortar for 1 hour. The mixture was uniaxially pressed into pellets $(30 \mathrm{~mm}$ in diameter and $8 \mathrm{~mm}$ in thickness after sintering) using a stainless steel die under a pressure of $15 \mathrm{MPa}$. Thereafter, the pressed pellet was sintered at $1773 \mathrm{~K}$ in the muffle furnace with a heating rate of $3 \mathrm{~K} / \mathrm{min}$ and 8 hour dwell. The total compositions of the prepared samples are listed in Table I.

In order to compare the properties of the prepared ceramic samples with the refractory used for ladle treatment, a commercial high-density $\mathrm{MgO}-\mathrm{C}$ brick supplied by SSAB-Oxelösund was also studied. This type of refractory is usually used as the working lining of steelmaking ladles. Disks were cut out from the brick. In order to simulate the decarburized layer, the brick was pre-fired to burn out the graphite at $1373 \mathrm{~K}\left(1100{ }^{\circ} \mathrm{C}\right)$ for 10 hour. The brick after decarburization contained 97.2 mass pet $\mathrm{MgO}, 1.6$ mass pet $\mathrm{CaO}$, and traces of other oxides according to the supplier.

The materials used for slag along with their suppliers and purity levels are presented in Table II. All powders were dried at $1173 \mathrm{~K}\left(900{ }^{\circ} \mathrm{C}\right)$ for $10 \mathrm{~h}$ to remove

Table I. Chemical Compositions of the Ceramic Substrates

\begin{tabular}{lcc}
\hline $\begin{array}{l}\text { Type of } \\
\text { Substrate }\end{array}$ & $\begin{array}{c}\text { MgO } \\
\text { (Mass Percent) }\end{array}$ & $\begin{array}{c}\text { Colloidal Alumina } \\
\text { (Mass Percent) }\end{array}$ \\
\hline MS0 & 100 & - \\
MS1 & 90 & 10 \\
MS2 & 80 & 20 \\
\hline
\end{tabular}

Table II. Supplier and Purities of Powders Used for Slag Preparation

\begin{tabular}{lll}
\hline Oxide & \multicolumn{1}{c}{ Supplier } & Purity \\
\hline $\mathrm{CaO}$ & Alfa Aesar & $99.95 \mathrm{pct}$ \\
$\mathrm{Al}_{2} \mathrm{O}_{3}$ & Alfa Aesar & $99.50 \mathrm{pct}$ \\
$\mathrm{MgO}$ & Sigma Aldrich & $>99 \mathrm{pct}$ \\
$\mathrm{SiO}_{2}$ & Alfa Aesar & $99.80 \mathrm{pct}$ \\
\hline
\end{tabular}

moisture. The powders of $\mathrm{CaO}$ (55 mass pct), $\mathrm{Al}_{2} \mathrm{O}_{3}$ (30 mass pct), $\mathrm{MgO}$ ( 8 mass pct), and $\mathrm{SiO}_{2}$ ( 7 mass pct) were mixed thoroughly in an agate mortar. The mixed powders were pressed into pellets (each about $2 \mathrm{~g}$, $11 \mathrm{~mm}$ in diameter and $10 \mathrm{~mm}$ in thickness) and stored in a desiccator before being used in the experiment.

\section{B. Setups}

To study the mechanism of reaction between molten slag and the ceramic substrates, a vertical furnace was used. The setup is schematically shown in Figure 1. The high-temperature furnace with super Kanthal heating elements was controlled using a B-type thermocouple (Pt-6 pet Rh/Pt-30 pet Rh). Another B-type thermocouple was placed just beneath the graphite sample holder. The alumina reaction tube was connected to a watercooled quenching unit made of brass. The whole reaction chamber was sealed using O-rings. To ensure efficient quenching of the sample, the quenching unit had two gas inlets that enabled injection of argon gas with a high flow rate onto the sample when it was in the quenching position.

The sample was held in the graphite holder. Many holes were made in the holder to reduce its heat capacity. A graphite connecter connected the graphite holder to a long steel tube. The steel tube was placed in the central axial position and connected to the lift (driven by motor) above the reaction chamber. The steel tube could be moved both downward and upward by the lift, while the system was kept gas tight by O-rings. Fast quenching was enabled by moving the graphite holder from the hot zone of the furnace to the water-cooled quenching unit in less than one second using the lift.

For each run, the ceramic pellet $(30 \mathrm{~mm}$ in diameter, $8 \mathrm{~mm}$ in thickness) was placed in the graphite sample holder with the slag pellet on its top. The sample was kept in the cooling chamber, when the reaction tube was

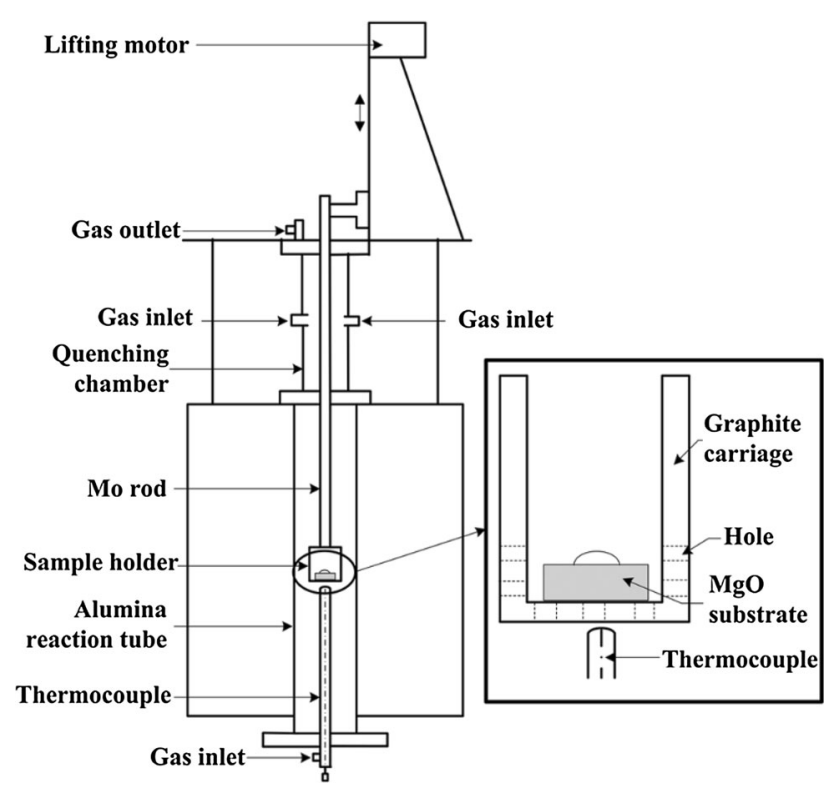

Fig. 1-Experimental setup. 
evacuated, and then flushed with argon gas. The furnace was then heated up. When the furnace reached the target temperature, the sample was lowered down step by step into the hot zone of the furnace from the quenching chamber (in about 20 minute). Moving the sample slowly to the high temperature zone would avoid the thermal shock of the reaction tube, and at the same time reduce the reaction time between slag and substrate before melting of the slag. The slag was allowed to react with the ceramic pellet for a predetermined time, before the sample holder was rapidly lifted to the quenching chamber and quenched by high flow of argon gas.

All the experiments were repeated more than 2 times to examine the reproducibility of the results. In this study, the criteria to determine the reproducibility were the penetration depth, liquid composition, as well as the phase distribution at the grain boundaries.

\section{Analysis}

The bulk density and apparent porosity of the sintered ceramics $\mathrm{MgO}$ with different amounts of colloidal alumina were measured by the Archimedes method using water as an immersion medium. It should be mentioned that the hydration of $\mathrm{MgO}$ would affect the accuracy of the apparent porosities and bulk densities when water was used as immersion medium due to the possible formation of $\mathrm{Mg}(\mathrm{OH})_{2}$. However, in view that the samples were sintered at high temperature and the density measurements in the water were fast, the uncertainty introduced by $\mathrm{MgO}$ hydration could be expected relatively small to affect the discussion. X-ray diffraction (XRD) analysis was carried out using a Bruker D8 Advance X-ray diffractometer (Karlsruhe, Germany; $\mathrm{Cu} \mathrm{K} \mathrm{K}_{\alpha}$ radiation generated at $40 \mathrm{kV}$ and $40 \mathrm{~mA}$ ), with $2 \theta$ ranging from $10 \mathrm{deg}$ to $80 \mathrm{deg}$ and a scanning speed of $6 \mathrm{deg} / \mathrm{min}$. The microstructure and chemical composition of the specimen were determined by a scanning electron microscope (SEM, Hitachi TM3100, Japan) with an energy dispersive spectroscopy (EDS) analyzer.

\section{RESULTS}

\section{A. MgO-In Situ Spinel Substrates}

The X-ray diffraction patterns of sintered $\mathrm{MgO}$ substrates with different amounts of colloidal alumina addition are shown in Figure 2. Because of the chemical reaction between $\mathrm{MgO}$ and $\mathrm{Al}_{2} \mathrm{O}_{3}$ during the sintering, the second phase, spinel is formed. As seen in the figure, in the absence of $\mathrm{Al}_{2} \mathrm{O}_{3}$ addition, only $\mathrm{MgO}$ phase is present. On the other hand, both MS1 and MS2 samples consist of two phases, namely $\mathrm{MgO}$ and spinel. The figure also shows that an increase of the colloid addition results in an increase of the intensity of the spinel peak.

SEM and EDS analyses were conducted to show the morphology of in situ spinel in the $\mathrm{MgO}$ matrix, and to examine its composition. The SEM images of the sintered MS0, MS1, and MS2 are presented in Figures 3(a) through (c), respectively. The sample of MS0

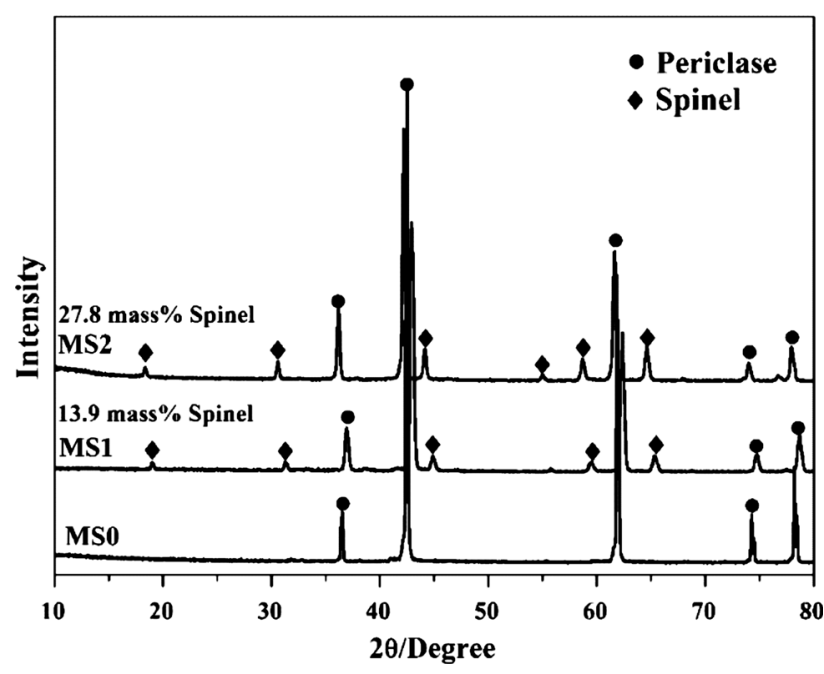

Fig. 2-X-ray diffraction patterns of $\mathrm{MgO}$ substrates with different amounts of colloidal alumina addition.

without colloidal alumina addition was much more porous than MS1 and MS2. A large amount of open pores can be seen in the matrix of $\mathrm{MgO}$ grains. $\mathrm{MgO}$ grains of sample MS2 showed the normal equiaxed morphology, while MS0 was sphere-like. Small spinel grains as a second phase located at the grain boundaries of $\mathrm{MgO}$ are observed in the samples of MS1 and MS2 (see Figures 3(b) and (c)). To obtain a clear morphology of spinel grains, fracture microstructure without surface polishing is inserted in Figure 3(c). It can be seen that classic octahedral spinel grains, sizing 2 to $4 \mu \mathrm{m}$, grow up around magnesia grains. The element mapping of $\mathrm{Al}$ is presented in Figure 3(d) for MS2. Al element is distributed uniformly in the Mg matrix. From Table III, EDS analysis reveals an element ratio 30.6/69.4 of the two oxides in the spinel phase. This ratio is quite near the stoichiometric $\mathrm{MgAl}_{2} \mathrm{O}_{4}$. The apparent porosities and bulk densities of $\mathrm{MgO}$ with different amounts of colloidal alumina addition are listed in Table IV. A density increase is observed with the increase of colloidal alumina addition, which corresponds with the porosity decrease. The difference in porosity confirms that the spinel formation plays a crucial role in ceramic bonding. It should be mentioned that the pore size would also have important impact on the slag infiltration. However, $\mathrm{MgO}$ substrates without addition of colloidal alumina and industrial $\mathrm{MgO}$ refractory with decarburization have a very porous structure. It consists of a large amount of "interconnected" irregular open pores. It is very difficult to obtain the accurate distribution of pore sizes. In Table IV, the obvious difference in porosity is intended to show relatively the role of colloidal alumina addition.

\section{B. Slag Penetration}

The penetration profiles of the three substrates after wetting tests of 30 minute at $1873 \mathrm{~K}\left(1600{ }^{\circ} \mathrm{C}\right)$ are shown in Figure 4. As indicated by the markers, slag has penetrated through $\mathrm{MgO}$ matrix to different depths. In 

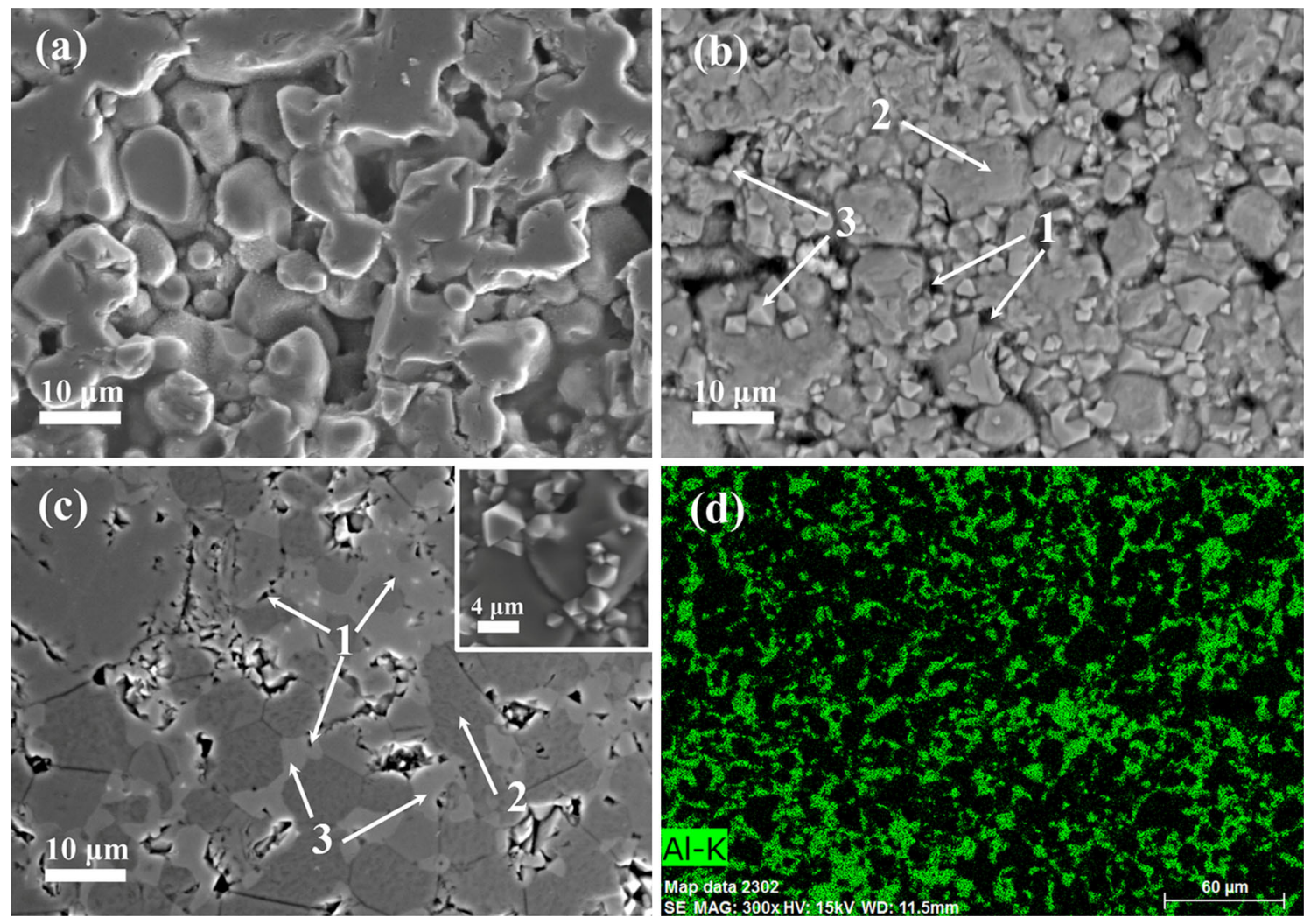

Fig. 3-SEM images of the samples; (a) MS0, (b) MS1, (c) MS2, and (d) element mapping of Al in sample MS2; Pores marked as 1, MgO marked as 2, and Spinel marked as 3 .

Table III. Elements Composition of Mg/Al for Spinel Phases

\begin{tabular}{lccc}
\hline Element & Series & $\begin{array}{c}\text { Norm. C } \\
\text { (Weight Percent) }\end{array}$ & $\begin{array}{c}\text { Atom. C } \\
\text { (Atomic Percent) }\end{array}$ \\
\hline Magnesium & K-series & 28 & 31 \\
Aluminum & K-series & 72 & 69 \\
\hline
\end{tabular}

Table IV. Apparent Densities and Porosities of $\mathrm{MgO}$ with Different Amounts of Alumina Addition

\begin{tabular}{lcc}
\hline Sample No. & Density $\left(\mathrm{g} / \mathrm{cm}^{3}\right)$ & Porosity (Percent) \\
\hline MS0 & 2.343 & 34.25 \\
MS1 & 2.780 & 19.74 \\
MS2 & 2.899 & 16.63 \\
\hline
\end{tabular}

both cases of MC and MS0, the components of the slag have reach the bottom of the pellet, while in the case of MS1 and MS2, the slag has penetrated to the levels of 6.5 and $4 \mathrm{~mm}$, respectively, from the upper surface of the pellet. The results reveal that the addition of colloidal alumina (as a consequence, the formation of the spinel phase) helps to limit the slag penetration into the $\mathrm{MgO}$ matrix. Detailed discussion about the depth of slag penetration and microstructure is given in the later sections.

The samples after the experiments in the vertical furnace are subjected to SEM and EDS analyses. The substrate is divided into 4 zones equally from the top to bottom (each zone is $2 \mathrm{~mm}$ ). To help the discussion, these zones are named as A, B, C, and D from the top to the bottom.

The phases present in the 4 zones are identical in the reacted MS0 substrate. For brevity, only the SEM microphotograph of Zone D of the MS0 sample is presented in Figure 5. Beside the $\mathrm{MgO}$ matrix, two phases are found at the grain boundaries of the $\mathrm{MgO}$ phase throughout the whole thickness, namely phase 2 and phase 3 . Note that only small amount of phase 3 is seen in the sample, while the amount of phase 2 is relatively big. According to EDS analysis, phase 2 has a composition of 1 to 3 mass pet $\mathrm{MgO}, 38$ to 41 mass pet $\mathrm{Al}_{2} \mathrm{O}_{3}$, and 56 to 59 mass pct $\mathrm{CaO}$. The composition of this phase (in the liquid region as indicated by the phase diagram $^{[21]}$ ) and the fact that it fills up the $\mathrm{MgO}$ grain boundaries indict this phase being liquid at the experimental temperature. Phase 3 has a composition close to $12 \mathrm{CaO} \cdot 7 \mathrm{Al}_{2} \mathrm{O}_{3}$. An examination of the phase diagram of the binary $\mathrm{CaO}-\mathrm{Al}_{2} \mathrm{O}_{3}{ }^{[21]}$ suggests that $12 \mathrm{CaO} \cdot 7 \mathrm{Al}_{2} \mathrm{O}_{3}$ is likely to precipitate from molten slag during quenching, since the melting temperature of this phase is below $1873 \mathrm{~K}\left(1600^{\circ} \mathrm{C}\right)$. Note that the content of $\mathrm{MgO}$ in the liquid phase was lower than initial slag composition. Besides, $\mathrm{SiO}_{2}$ content after each test has decreased considerably. The amount of Si element is hardly to detect in the penetrated slag. One plausible explanation for the low $\mathrm{MgO}$ content and low $\mathrm{SiO}_{2}$ content in the infiltrated slag is the low oxygen potential in the system. The oxygen potential employed is very close to that 


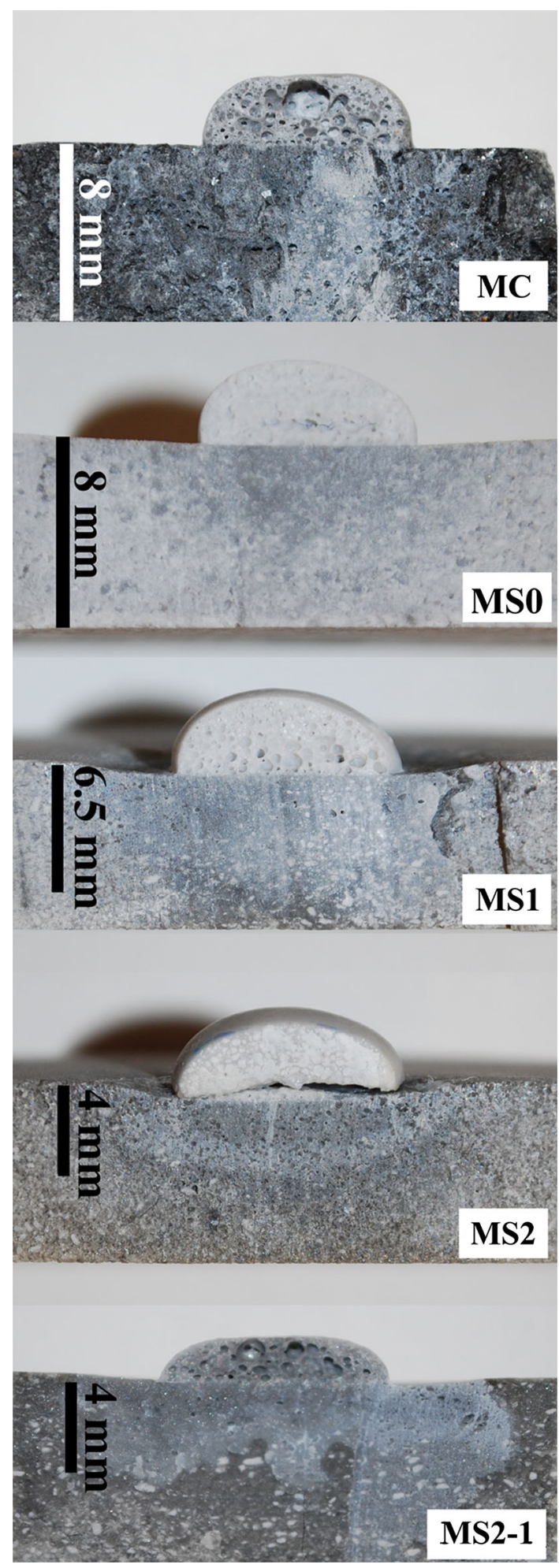

Fig. 4-Penetration profiles after the tests.

prevailing in a ladle furnace, about $\mathrm{P}_{\mathrm{O} 2}=10^{-16} \mathrm{~atm}$. The formation of $\mathrm{Mg}$ gas and $\mathrm{SiO}$ gas at such low oxygen potential would well explain the loss of both $\mathrm{MgO}$ at the surface and $\mathrm{SiO}_{2}$ in the slag.

The phases found in MS1 and MS2 samples after reaction vary with the position of the zone. As an example, Figures 6(a) through (d) present the SEM

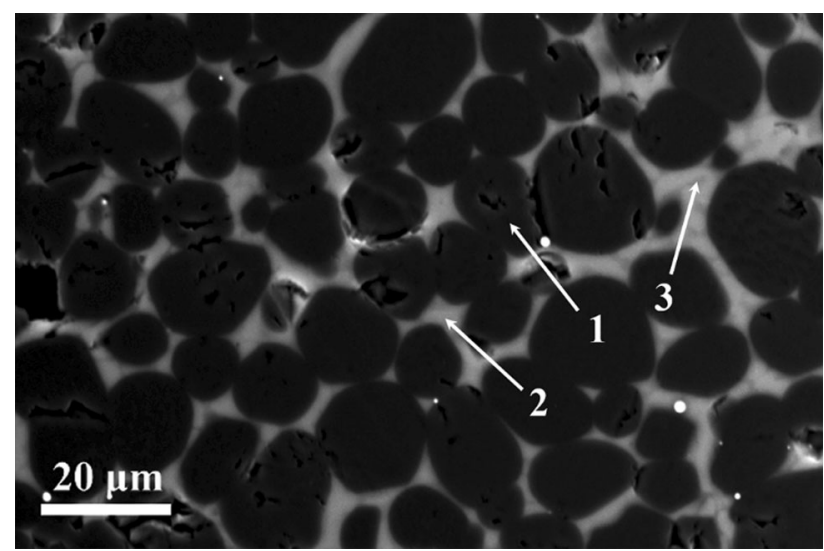

Fig. 5-SEM image of MS0 substrate in Zone $\mathrm{D}$; $\mathrm{MgO}$ matrix marked as 1 , liquid phase marked as 2 , and $12 \mathrm{CaO} \cdot 7 \mathrm{Al}_{2} \mathrm{O}_{3}$ marked as 3 .

microphotographs of Zones A, B, C, and D in the reacted MS2 substrate. In Zone A, the phases present are identical to the phases in the substrate MS0. The $\mathrm{MgO}$ grains in the matrix are surrounded by two phases, which are identified as $12 \mathrm{CaO} \cdot 7 \mathrm{Al}_{2} \mathrm{O}_{3}$ and liquid phase.

As the slag penetrates deeper (Zone B, see Figure 6(b)), the continuous liquid phase is still the major phase at the grain boundaries. It is worthwhile to mention that the content of $\mathrm{Al}_{2} \mathrm{O}_{3}$ in the liquid phase has increased comparing to the liquid in Zone $\mathrm{A}$. The composition of the liquid is about 5 to 7 mass pet $\mathrm{MgO}$, 42 to 45 mass pet $\mathrm{Al}_{2} \mathrm{O}_{3}$ and 50 to 52 mass pet $\mathrm{CaO}$. The increased content of $\mathrm{Al}_{2} \mathrm{O}_{3}$ is because of the dissolution of in situ spinel into the liquid. Small amount of spinel grains (phase 4) is found around the $\mathrm{MgO}$ matrix. Besides, tiny pieces of $\mathrm{CaO} \cdot \mathrm{Al}_{2} \mathrm{O}_{3}(\mathrm{CA})$ phase $(1$ to $2 \mu \mathrm{m})$ are detected on the surface of "unreacted" spinel grains, marked as 5 .

When the liquid slag goes down into Zone $\mathrm{C}$, there is a clear difference in the phase distribution. Instead of liquid phase filling up the grain boundaries, solid phases occupy most of spaces among $\mathrm{MgO}$ grains (Figure 6(c)). In this zone, liquid phase is a minor phase surrounding the solid pieces. In comparison with Zone B, more spinel grains are seen in this zone, suggesting that less spinel has dissolved into the liquid phase in this zone. The major phase at the grain boundaries is the light gray $\mathrm{CaO} \cdot \mathrm{Al}_{2} \mathrm{O}_{3}$ phase that formed as a continuous, adherent layer on the spinel surface. While the liquid phase is descending through the $\mathrm{MgO}$ matrix, the spinel phase is dissolved into the liquid. The dissolution of spinel increases the contents of both $\mathrm{Al}_{2} \mathrm{O}_{3}$ and $\mathrm{MgO}$ in the liquid. As indicated by the phase diagram, ${ }^{[21]}$ the increase of $\mathrm{Al}_{2} \mathrm{O}_{3}$ will lead to the precipitation of the $\mathrm{CaO} \cdot \mathrm{Al}_{2} \mathrm{O}_{3}$ phase at $1873 \mathrm{~K}\left(1600{ }^{\circ} \mathrm{C}\right)$. At the same time, the dissolution of the spinel phase is also stopped due to the increase of the activities of $\mathrm{Al}_{2} \mathrm{O}_{3}$ and $\mathrm{MgO}$ in the liquid. It is interesting to mention that a few round darker grains are found in Zone $\mathrm{C}$. These grains are identified as $\mathrm{CaO} \cdot \mathrm{MgO} \cdot \mathrm{Al}_{2} \mathrm{O}_{3}$ (CMA) solid solution (marked as phase 6). The presence of the $\mathrm{CaO} \cdot \mathrm{MgO}$. $\mathrm{Al}_{2} \mathrm{O}_{3}$ phase is also explained by the phase diagram of the $\mathrm{Al}_{2} \mathrm{O}_{3}-\mathrm{CaO}-\mathrm{MgO}$ ternary. 

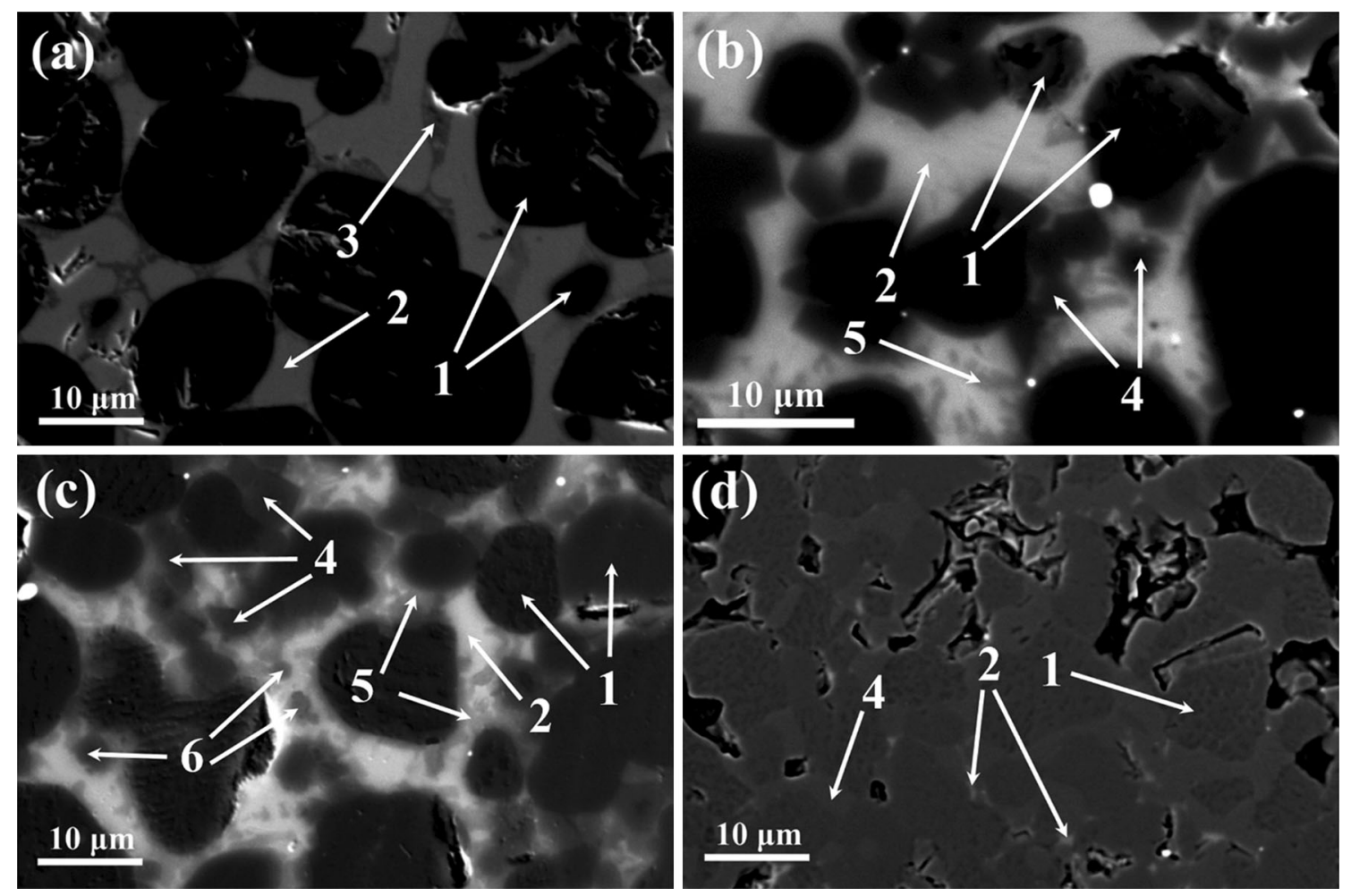

Fig. 6- SEM image of MS2 in $(a)$ Zone A, $(b)$ Zone B, $(c)$ Zone C, and $(d)$ Zone D; MgO matrix marked as 1, liquid phase marked as 2, $12 \mathrm{CaO} \cdot 7 \mathrm{Al}_{2} \mathrm{O}_{3}$ marked as 3 , spinel as $4, \mathrm{CaO} \cdot \mathrm{Al}_{2} \mathrm{O}_{3}$ as 5 , and $\mathrm{CMA}$ solid solution marked as 6 .

In Zone $\mathrm{D}$, the bottom region of the substrate, the slag penetration is absent. As shown in Figure 6(d), only the $\mathrm{MgO}$ and spinel phases are detected. The morphology of this zone is very similar as the substrate before reaction shown in Figure 3(c). The phase distributions in Figures 6(a) through (d) show evidently the formation of the solid phases $\left(\mathrm{CaO} \cdot \mathrm{Al}_{2} \mathrm{O}_{3}\right.$ and $\mathrm{CaO} \cdot \mathrm{MgO}$. $\mathrm{Al}_{2} \mathrm{O}_{3}$ ) due to the saturation of $\mathrm{Al}_{2} \mathrm{O}_{3}$ in the liquid phase at the grain boundaries. The precipitation of the solid phases would block the open pores of the substrate finally. This would stop further slag penetration.

Table $\mathrm{V}$ summarizes the phases found in grain boundaries of different zones after the experiments. In the table, MC stands for the substrate cut out from a brick of carbon bearing $\mathrm{MgO}$ refractory for the use in ladle lining. After 30 minute, slag has penetrated into the refractory through the entire thickness of the sample, as seen in Figure 4(MC). The phases present in each zone after reaction are identical as the ones found in the reacted MS0 substrate. This aspect is exemplified by the phases in Zone D shown in Figure 7. It should be pointed out the comparison between the industrial bricks and the sintered dense samples should be used with precaution. Real comparison should be made only when the two samples have similar grain sizes of the MgO particles and similar porosities. This would be the topic in the coming study.

To examine whether the reacted layer in the reacted MS2 substrate can further help to block the slag penetration in the next heat of the ladle treatment, experiment of MS2-1-Run1 was conducted. In this experiment, the substrate of type MS2 was first reacted with slag with the same experimental condition as MS2Run1. The substrate was used again to react with new slag in a new experiment.

The double penetration on MS2-1-Run1 did increase the corrosion area, but only in the horizontal direction. Comparison of the two samples indicates that the increase of penetration in depth is negligible (shown by SEM analysis). In view that the ladle is used for many heats, this double penetration experiments are very necessary. For the same reason, the focus is given to the depth of the slag attract in the case of double penetration experiments. Only traces of liquid phase (almost negligible) are detected in Zone D in the sample. In this zone, the major phase at the grain boundaries is spinel.

\section{DISCUSSION}

As shown in Table $\mathrm{V}$, all the experiments are repeated. The results are reproducible. In fact, in most cases, the experiments are repeated a few times.

\section{A. Slag Penetration}

As shown in Figure 3(a), there is a considerable amount of open pores left in the substrate. The probable cause of the case is the poor sinterability of coarse $\mathrm{MgO}$ powders. The addition of colloidal alumina has positive effect on the densification as revealed by the results in Table IV. This finding is in agreement with the observation by Ghosh et al..$^{[9,22,23]}$ This can be attributed to 
Table V. Phases Found at the Grain Boundaries of MgO After Reaction

\begin{tabular}{|c|c|c|c|c|c|c|}
\hline Substrate & Test & Zone & $\begin{array}{l}\text { Amount of } \\
\text { Liquid Phase }\end{array}$ & Spinel & $\mathrm{CaO} \cdot \mathrm{Al}_{2} \mathrm{O}_{3}$ & CMA \\
\hline \multirow[t]{8}{*}{ MS0 } & \multirow[t]{4}{*}{ Run1 } & A & major & - & - & - \\
\hline & & B & major & - & - & - \\
\hline & & $\mathrm{C}$ & major & - & - & - \\
\hline & & $\mathrm{D}$ & major & - & - & - \\
\hline & \multirow[t]{4}{*}{ Run2 } & A & major & - & - & - \\
\hline & & $\mathrm{B}$ & major & - & - & - \\
\hline & & $\mathrm{C}$ & major & - & - & - \\
\hline & & $\mathrm{D}$ & major & - & - & 一 \\
\hline \multirow[t]{8}{*}{ MS1 } & \multirow[t]{4}{*}{ Run1 } & A & major & - & - & - \\
\hline & & B & major & - & - & 一 \\
\hline & & $\mathrm{C}$ & major & yes & - & - \\
\hline & & $\mathrm{D}$ & minor & major & yes & - \\
\hline & \multirow[t]{4}{*}{ Run2 } & A & major & - & - & - \\
\hline & & B & major & - & - & - \\
\hline & & $\mathrm{C}$ & major & yes & - & - \\
\hline & & $\mathrm{D}$ & minor & major & yes & - \\
\hline \multirow[t]{8}{*}{ MS2 } & \multirow[t]{4}{*}{ Run1 } & A & major & - & - & - \\
\hline & & B & major & minor & yes & - \\
\hline & & $\mathrm{C}$ & minor & major & minor & yes \\
\hline & & $\mathrm{D}$ & - & major & 一 & - \\
\hline & \multirow[t]{4}{*}{ Run2 } & A & major & - & - & - \\
\hline & & $\mathrm{B}$ & major & minor & yes & - \\
\hline & & $\mathrm{C}$ & minor & major & minor & yes \\
\hline & & $\mathrm{D}$ & - & major & - & - \\
\hline \multirow[t]{8}{*}{ MS2-1 } & \multirow[t]{4}{*}{ Run1 } & A & major & - & - & - \\
\hline & & B & major & minor & yes & - \\
\hline & & $\mathrm{C}$ & minor & major & minor & - \\
\hline & & $\mathrm{D}$ & trace & major & - & - \\
\hline & \multirow[t]{4}{*}{ Run2 } & A & major & - & - & - \\
\hline & & B & major & minor & yes & - \\
\hline & & $\mathrm{C}$ & minor & major & minor & - \\
\hline & & $\mathrm{D}$ & trace & major & - & - \\
\hline \multirow[t]{8}{*}{$\mathrm{MC}$} & \multirow[t]{4}{*}{ Run1 } & A & major & - & - & - \\
\hline & & B & major & - & - & - \\
\hline & & $\mathrm{C}$ & major & - & - & - \\
\hline & & $\mathrm{D}$ & major & - & - & - \\
\hline & \multirow[t]{4}{*}{ Run2 } & A & major & - & - & - \\
\hline & & B & major & - & - & - \\
\hline & & $\mathrm{C}$ & major & - & - & - \\
\hline & & $\mathrm{D}$ & major & - & - & - \\
\hline
\end{tabular}

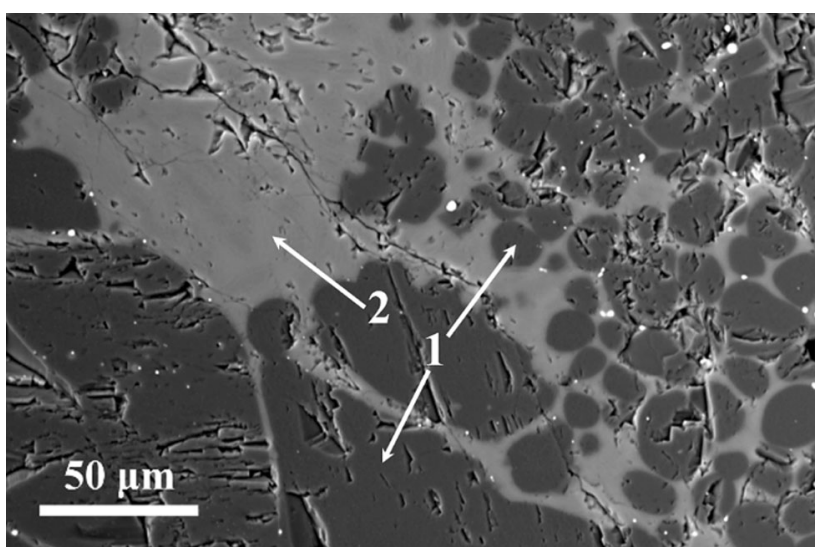

Fig. 7- $\mathrm{SEM}$ image of $\mathrm{MC}$ substrate in Zone $\mathrm{D}$; $\mathrm{MgO}$ matrix marked as 1 , liquid phase marked as 2 . the formation of in situ spinel phase. Small spinel grains as the second phase fill up the inter-granular gaps (or open pores) between magnesia grains, playing a role of an excellent ceramic bonding. This bonding contributes to dense structures with lower porosity. Another aspect that also makes contribution to the densification is the tiny size of the $\mathrm{Al}_{2} \mathrm{O}_{3}$ particles in the colloidal suspension. Finer particles of alumina could enhance the $\mathrm{MgO}-\mathrm{Al}_{2} \mathrm{O}_{3}$ inter-diffusion driving force; and moreover, colloidal suspension could lower self-agglomeration. ${ }^{[19,24]}$

In the case of commercial carbon bearing $\mathrm{MgO}$ refractory, the liquid slag is the primary phase at the grain boundaries. In general, the slag penetrating depends on the physical properties of substrates, such as apparent porosity, grain boundaries, cracks, etc. ${ }^{[25]}$ In $\mathrm{MgO}$ refractory, large amounts of open pores are the main channels of slag penetration. Capillary sucking 
pressure is the major driving force for the infiltration of the liquid. Although the grain size of $\mathrm{MgO}$ particles in MS0 samples is somewhat different from that of the industrial refractory $\mathrm{MC}$, the same behavior of slag penetration is observed. Even the phases found among the $\mathrm{MgO}$ grains are identical in these two cases. It could be expected that the present finding would throw some lights on the development of new refractory materials for making clean steel. For example, colloidal alumina could be used to replace carbon as additives in industrial $\mathrm{MgO}$ refractory. However, a good refractory based on $\mathrm{MgO}$ should also have improved mechanical properties and be economically sound. These aspects would need further detailed studies (which is currently carried out in the present group).

As already mentioned in the introduction part, ladle glaze is a very important source of the formation of inclusions. ${ }^{[1-8]}$ When the top slag goes down following the steel during the draining of the ladle, it adheres to the ladle lining. The adhered slag penetrates into the open pores of the $\mathrm{MgO}$ refractory. This phenomenon is well demonstrated by the present experimental results with MS0 and MC samples. The slag-infiltrated layer would not be easily removed because of the $\mathrm{MgO}$ matrix. In the next heat, the movement of the liquid steel near the wall would flush off pieces of the slag-infiltrated layer resulting in macro calcium aluminate inclusions. ${ }^{[5,8]}$

\section{B. Effect of Colloidal Alumina Addition}

As discussed in the result part, the addition of 20 mass pet colloidal alumina can efficiently limit the slag penetration. The increased resistance to slag penetration by spinel formation is in good agreement with the observation of Ganesh et al. ${ }^{[12]}$ As seen in Table $\mathrm{V}$, very little amount of liquid phase is observed $4 \mathrm{~mm}$ away from the slag-MS2 interface. A lot of spinel particles are still found in Zone $\mathrm{C}$ after reaction of 30 minute. In Zone D, no liquid phase is detected. The morphology of Zone D is more or less the same as the prepared ceramic. Putting the reacted substrate into contact again with new slag does not show serious slag penetration (MS2-1-Run1). In Zone D of the doubly used substrate, no liquid phase is seen. It is evident that adding colloidal alumina into $\mathrm{MgO}$ has a positive effect on penetration resistance. The suppressed penetration of slag could be partly due to the improvement of the microstructure of the substrate, since the decreased porosity by spinel bonding could lead to the reduction of sucking pressure. ${ }^{[13]}$ The presence of $\mathrm{Al}_{2} \mathrm{O}_{3}$ in the spinel phase plays another important role in improving the penetration resistance. This role is evidently brought out by the variation of phases in different zones of the reacted substrate, MS2 (even MS1). To elaborate the discussion, the average compositions of the liquid phase in different zone of reacted MS2 are presented in the $\mathrm{Al}_{2} \mathrm{O}_{3}-\mathrm{CaO}-\mathrm{MgO}$ phase diagram ${ }^{[21]}$ (Figure 8). The dissolution of the spinel phase (MA) results in the increase of the contents of $\mathrm{Al}_{2} \mathrm{O}_{3}$ and $\mathrm{MgO}$. This aspect is clearly shown by the fact that the composition of the liquid moves toward MA, as the slag penetrates through

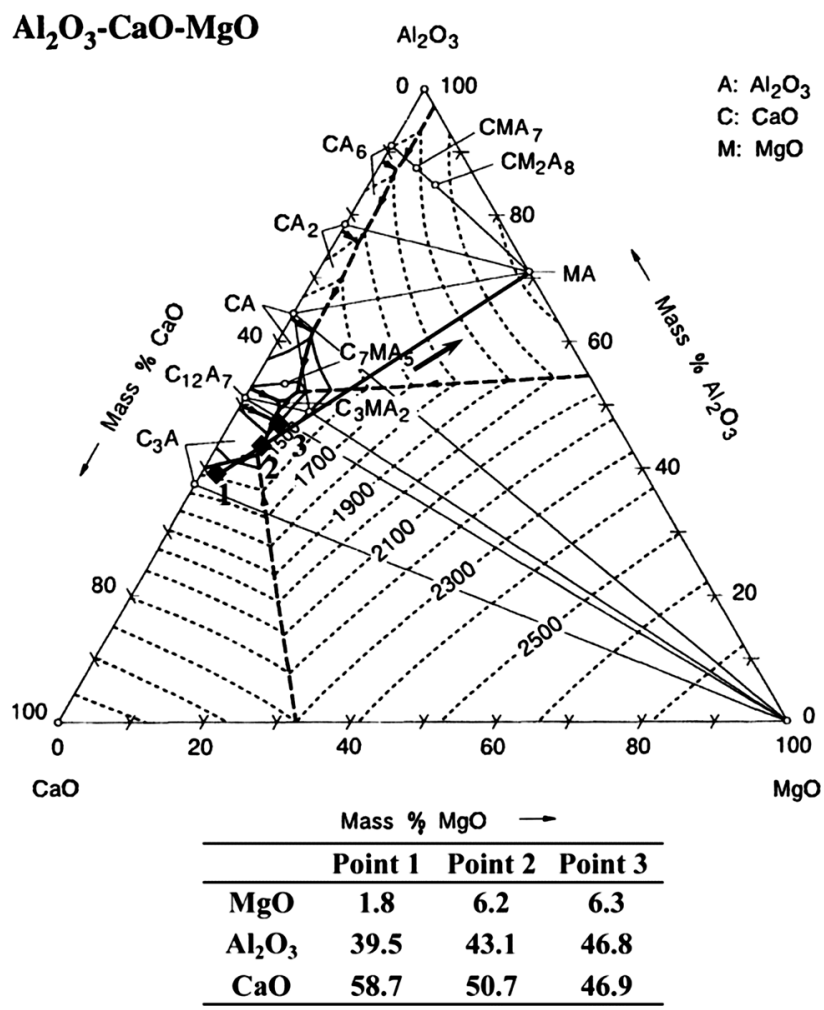

Fig. $8-\mathrm{CaO}-\mathrm{Al}_{2} \mathrm{O}_{3}-\mathrm{MgO}$ phase diagram with the compositions of the liquid phase found in different zones of the MS2 substrate.

the substrate. It is evident that the local thermodynamic equilibrium varies with the depth of the penetration. The dissolution of MA would finally lead to the vanishing of the liquid phase and the formation of $\mathrm{CaO} \cdot \mathrm{Al}_{2} \mathrm{O}_{3}$ and even CMA solid solution. Note that both the melting temperatures of CA and CMA solid solution are above $1873 \mathrm{~K}\left(1600{ }^{\circ} \mathrm{C}\right)$. The formation of the solid phase(s) would completely block the pores and stop further slag penetration. It is likely that the presence of in situ spinel would slow down mechanically the penetration of the liquid phase, therefor giving time for the liquid phase to react with the substrate component (in the present case the spinel phase). However, the most profound contribution of spinel phase is its dissolution into the liquid, leading finally the vanishing of the liquid phase.

When the liquid slag has just penetrated into the substrate, the main mechanism of the reaction between slag and refractory would be the dissolution of spinel into liquid phase. When more and more spinel has dissolved into the liquid slag as the liquid penetrating, the liquid phase would be saturated by spinel. Further reaction of the liquid phase and MA leads to the formation of other solid phase(s) and finally vanish of the liquid. The blocking effect by the presence of spinel particles at the $\mathrm{MgO}$ grains functions even when new slag is used. This aspect is evidently brought out by the result of MS2-1-Run1, where the reacted MS2 substrate is reacted with fresh slag in the second run. The phase distribution with the depth is very similar to the "onetime" (MS2-Run1) penetration. This means that those solid phases which have been formed previously become 
the "real" barriers to inhibit the slag penetration. It should be pointed out that the change of viscosity of the oxide liquid could have certain influence on the penetration and corrosion. It is very difficult to identify the contribution of the formation of solid particles and the increased viscosity on the inhabitation of slag penetration. Nevertheless, it is expected that when the fraction of solid phase increases, the contribution of solid phase would be dominating. It is also interesting to mention that the viscosity of basic ladle slag has actually negligible effect on the formation of inclusions from the lining in the ladle. ${ }^{[26]}$ Table $\mathrm{V}$ also indicates that the amount of addition of colloidal alumina is essentially important. Addition of 10 mass pet has much less impact on the resistance of slag penetration, while 20 pct addition leads to substantial improvement.

The present result suggests a potential approach to generate new $\mathrm{MgO}$-based refractory for making clean steel. However, the results should only be considered as preliminary. The following aspect must be carefully studied. (1) Using much coarser grains of $\mathrm{MgO}$ to verify the applicability of the new approach. (2) The applicability of the material with respect to the mechanical properties must be studied. (3) The amount of addition of colloidal alumina needs to be further examined. (4) The interaction between the refractory and steels with different compositions needs to be investigated.

\section{SUMMARY}

MgO-in situ spinel substrates were prepared by sintering the mixtures of coarse $\mathrm{MgO}$ and colloidal alumina at $1773 \mathrm{~K}\left(1500{ }^{\circ} \mathrm{C}\right)$ for 8 hour. $\mathrm{MgAl}_{2} \mathrm{O}_{4}$ spinel phase was formed during sintering in the substrates. The presence of spinel phase decreased the porosity of substrates. Addition of 20 mass pet colloidal alumina into $\mathrm{MgO}$ substrate showed a porosity of $16.6 \mathrm{pct}$.

In situ spinel was found to have positive effect on the resistance of slag penetration. Addition of 20 mass pct colloidal alumina could greatly limit the slag penetration into the $\mathrm{MgO}$ substrate. The suppressed penetration of slag could be partly due to the decreased porosity by spinel bonding which led to the reduction of sucking pressure. The presence of $\mathrm{Al}_{2} \mathrm{O}_{3}$ in the spinel phase played another important role in improving the penetration resistance. The dissolution of the spinel phase resulted in the increase of the contents of $\mathrm{Al}_{2} \mathrm{O}_{3}$ and $\mathrm{MgO}$ in the liquid oxide phase. The formation of solid oxide phases, $\mathrm{CaO} \cdot \mathrm{Al}_{2} \mathrm{O}_{3}$ and $\mathrm{CaO} \cdot \mathrm{MgO} \cdot \mathrm{Al}_{2} \mathrm{O}_{3}$ at the grain boundaries would create the barriers to hinder further penetration. The results suggested a possible solution to improve the resistance of $\mathrm{MgO}$-based refractory to produce steel having good cleanness.

\section{ACKNOWLEDGMENT}

The authors are thankful for the financial support of China Scholarship Council in the form of scholarship to the first author.

\section{REFERENCES}

1. G.J. Hassall, K.G. Bain, N. Jones, and M.O. Warman: Ironmak. Steelmak., 2002, vol. 29, pp. 383-89.

2. S. Riaz, K.C. Mills, and K. Bain: Ironmak. Steelmak., 2002, vol. 29 , pp. $107-13$

3. K. Beskow, J. Jia, C.H.P. Lupis, and D. Sichen: Ironmak. Steelmak., 2002, vol. 29, pp. 427-35.

4. K. Beskow and D. Sichen: Ironmak. Steelmak., 2004, vol. 31, pp. 393-400.

5. K. Beskow and N. Sano: Iron Steel Technol., 2006, vol. 3, pp. $103-$ 17.

6. C.W. Bale, P. Chartrand, S.A. Degterov, G. Eriksson, K. Hack, R. Ben Mahfoud, J. Melançon, A.D. Pelton, and S. Petersen: CALPHAD, 2002, vol. 26, pp. 189-228.

7. I.H. Jung, J.H. Son, S.M. Jung, H. Gaye, and H.G. Lee: Proceedings ICS 2008: The 4th International Congress on the Science and Technology of Steelmaking. 2008. pp. 395-98.

8. M. Song, M. Nzotta, and D. Sichen: Steel Res. Int., 2009, vol. 80, pp. 753-60.

9. G.R. Eusner and D.H. Hubble: J. Am. Ceram. Soc., 1960, vol. 43, pp. 292-97.

10. S. Zhang and W.E. Lee: Spinel-containing Refractories, Refractories Handbook, Marcel Dekker Inc., New York, 2004, pp. 215-58.

11. K. Goto, B.B. Argent, and W.E. Lee: J. Am. Ceram. Soc., 1997, vol. 80 , pp. $461-71$.

12. I. Ganesh, S. Bhattacharjee, B.P. Saha, R. Johnson, K. Rajeshwari, R. Sengupta, M.V. Ramana Rao, and Y.R. Mahajan: Ceram. Int., 2002, vol. 28, pp. 245-53.

13. M. Bavand-Vandchali, F. Golestani-Fard, H. Sarpoolaky, H.R. Rezaie, and C.G. Aneziris: J. Eur. Ceram. Soc., 2008, vol. 28, pp. 563-69.

14. M.K. Cho, G.G. Hong, and S.K. Lee: J. Eur. Ceram. Soc., 2002, vol. 22, pp. 1783-90.

15. M.A.L. Braulio, A.G. TombaMartinez, A.P. Luz, C. Liebske, and V.C. Pandolfelli: Ceram. Int., 2011, vol. 37, pp. 1935-45.

16. L.A. Díaz, R. Torrecillas, A.H. de Aza, and P. Pena: J. Eur. Ceram. Soc., 2007, vol. 27, pp. 4623-31.

17. T.M. Besmann: CALPHAD, 2008, vol. 32, pp. 466-69.

18. A.P. Luz, A.G. Tomba Martinez, M.A.L. Braulio, and V.C. Pandolfelli: Ceram. Int., 2011, vol. 37, pp. 1191-201.

19. M.A.L. Braulio, M.F.L. Piva, G.F.L.E. Silva, and V.C. Pandolfelli: J. Am. Ceram. Soc., 2009, vol. 92, pp. 559-62.

20. M.A.L. Braulio, G.G. Morbioli, L.R.M. Bittencourt, and V.C. Pandolfelli: J. Am. Ceram. Soc., 2010, vol. 93, pp. 2606-10.

21. V. D. Eisenhüttenleute: Slag Atlas., Verlag Stahleisen GmbH, 1995.

22. A. Ghosh, R. Sarkar, B. Mukherjee, and S.K. Das: J. Eur. Ceram. Soc., 2004, vol. 24, pp. 2079-85.

23. K. Gotod and W.E. Lee: J. Am. Ceram. Soc., 1995, vol. 78, pp. $1753-60$.

24. M. Nouri-Khezrabad, M.A.L. Braulio, V.C. Pandolfelli, F. Golestani-Fard, and H.R. Rezaie: Ceram. Int., 2013, vol. 39, pp. 3479-97.

25. W.E. Lee and S. Zhang: Int. Mater. Rev., 1999, vol. 44, pp. 77104

26. M. Song, M. Nzotta, and D. Sichen: Ironmak. Steelmak., 2011, vol. 38 , pp. 584-89. 